\title{
LA REBELDÍA HUMANISTA Y LA EDUCACIÓN SOCRÁTICA EN ALBERT CAMUS
}

\author{
ÁNGEL RAMÍREZ MEDINA \\ Universidad de Almería
}

\begin{abstract}
RESUMEN: El artículo parte del análisis camusiano del problema del mal, en diálogo con las respuestas dadas por el Gnosticismo griego y el cristianismo. En este contexto, se habla del fracaso de las teodiceas, ejemplificaciones de lo que Camus considera la «rebeldía metafísica». A continuación, se reflexiona sobre dos categorías existenciales (el tiempo y el silencio), que constituyen contraargumentos ante la condena de la naturaleza humana por parte de las versiones más ortodoxas del cristianismo y las filosofías racionalistas. Camus construye una antropodicea cuyo eje está en una rebeldía humanista y transformadora, limitada en su praxis y aspiraciones por valores morales que ella misma genera y que confieren un sentido relativo a la existencia. El artículo finaliza con una reflexión en torno a la educación como poderoso instrumento de transformación social.
\end{abstract}

PALABRAS CLAVE: mal; gnosticismo; teodicea; antropodicea; culpa; nihilismo; rebeldía; educación; Sócrates.

\section{The Humanistic rebellion and the Socratic education in Albert Camus}

ABSTRACT: The article departs from the analysis about the problem of evil in Camus, in dialogue with the answers given by the Greek gnosticism and the Christianity. In this context we speak about the failure of the theodicies, example of what Camus considers the «metaphysical rebellion». Next, we think about two existential categories (time and silence) which constitute counter-arguments faced with the condemnation of the human nature from the most orthodox versions of the Christianity and the rationalist philosophies. Camus makes an anthropodicy speech whose main idea is a humanist, transforming rebellion, limited in its praxis and aspirations for moral values generated by itself, which confer a relative sense to the existence. The article ends with a reflection about education as a powerful resource of social transformation.

KEY WORD: Evil; Gnosticism; Theodicy; Anthropodicy; Fault; Nihilism; Rebellion; Education; Socrates.

Horae, dum saltant, nostras vorant ${ }^{1}$

En noviembre de 2013, se cumplieron cien años del nacimiento de Albert Camus en Dréan (Mondovi durante la colonización francesa), un pequeño pueblo argelino, luminoso, como fue su infancia. Este primer centenario puso de manifiesto la buena salud de que goza su obra a tenor de las numerosas reediciones, así como estudios e investigaciones que siguen viendo la luz en todo el mundo.

Camus creció como un niño feliz que gozaba de los sencillos tesoros ofrecidos generosamente para todos, pobres y ricos: el mar, el sol o la amistad. Pero muy pronto, la enfermedad vendría a ensombrecer este frágil paraíso, dando paso a

1 Sentencia escrita en el campanario de la iglesia de Lourmarin, próxima a la casa de Camus. 
cavilaciones que lo llevarán a la filosofía y a la creación literaria, con dos problemas existenciales que actúan como eje de su obra: el mal y la muerte. El hombre rebelde y el hombre absurdo son los modelos antropológicos propiciados por ellos, respectivamente. Ambos elementos cuestionan el sentido de la existencia que Camus quiere sostener renunciando, no obstante, a toda forma de escatología, sea ésta trascendente o histórica. Porque junto al Camus del absurdo y el nihilismo, existe el de la rebeldía y la esperanza, que es también del amor; categoría en torno a la cual, según su propio proyecto, iba a pivotar su obra ensayística y literaria, cuando le sorprendió la muerte. El 29 de diciembre de 1959, seis días antes de morir, envió a la revista argentina Reconstruir sus respuestas manuscritas a un formulario de entrevista (Marin, 2013, pp. 319-320), que apareció en el número de enero-febrero de 1960. Al ser preguntado en ella sobre la manera de mejorar el mundo, respondió: «Aimer quand on peu. Et ne pas haïr, si l'on peut». («Amar cuando se pueda. Y no odiar, si se puede $»^{2}$ ). Para seguir amando, le faltó tiempo y, tal vez, también palabras. El tiempo y el silencio son categorías existenciales con presencia constante en su obra. En efecto, como símbolos del sinsentido, Camus utiliza tanto el tiempo, bajo la fórmula de «eterno presente», como el silencio ${ }^{3}$. De ello dan prueba el protagonista de L'étranger, relatos breves como Les muets y obras teatrales como Le malentendu. En Le Mythe de Sisyphe, Camus establece que lo absurdo nace de una confrontación entre la llamada humana y el silencio irracional del mundo (Camus, 1942, II, pp. 117-118). El silencio es asimismo la última de las imposiciones del personaje de La peste en L'état de siège. También se refiere al «escandaloso silencio de Dios» ante el sufrimiento de las víctimas inocentes. En Sísifo, hallamos una imagen precisa del eterno presente y del silencio, de la conexión entre el absurdo, la incomunicación y la maldición del tiempo.

\section{Helenismo y CRISTIANISMO FRENTE al PROBlema DEL MAL}

En su trabajo final de licenciatura de 1936, Camus estudia las relaciones entre helenismo y cristianismo. En su opinión, las aportaciones esenciales de esta religión, desde el punto de vista filosófico, son la fraternidad universal (llega a hablar de una moral superior - Camus, 1936, p. 1234-), y el rechazo de la omnipotencia de la razón confrontada a los misterios (pp. 1304-1306).

En la primera parte de este trabajo, expone el cristianismo evangélico y resume con estas palabras sus características ideológicas: «Rechazo de la especulación, interés práctico y religioso, primacía de la fe, pesimismo respecto al ser humano e inmensa esperanza que nace de la Encarnación» (p. 1239). Después, se ocupa de la Gnosis como intento de diálogo intelectual greco-cristiano.

Fruto del encuentro que, a partir del siglo II, tiene lugar entre la religión cristiana y la filosofía griega, nace el Gnosticismo, que Camus define como una reflexión que emplea conceptos griegos para arrojar luz sobre misterios cristianos. En efecto,

\footnotetext{
2 La traducción al español de los textos de Camus que se citan en este artículo es mía.

3 «Esta impasibilidad y esta grandeza del hombre sin esperanza, este eterno presente, eso precisamente que teólogos perspicaces han llamado el infierno». (Camus 1939, p. 80).
} 
Tertuliano, fiel a su máxima «Creo porque es absurdo», reprochaba a los gnósticos el «escándalo» de creer que a los Evangelios pudiera unirse una explicación racional acerca del mal. La primera generación gnóstica, a comienzos del siglo II, entronca con la tradición pitagórica y defiende el carácter salvífico del conocimiento de la divinidad. A partir del problema del mal, el gnosticismo desarrolla ya una primera teoría acerca del pecado original como culpa universal. El interés de Camus por el gnosticismo no es extraño, dada la clara proximidad que existe entre los temas y posiciones gnósticos y el existencialismo moderno (Cfr. Jonas, 1972, pp. 279-301).

Tras abordar el pensamiento de Plotino, Camus estudia a Agustín de Hipona, un pensador abrumado ante la presencia del mal en nuestras vidas. Desde posiciones cristianas, la filosofía intenta afrontar por primera vez el problema de cómo hacer compatible la existencia del Dios bueno con la realidad del mal en su triple dimensión (metafísica, física y moral).

En relación con el mal, dice descubrir en el platonismo su vinculación con la materia y su naturaleza completamente negativa (San Agustín 397, VII, 12 y VIII, 13); pero, aun admitiendo esta concepción ontológica, será en el misterio cristiano de la Encarnación donde cree hallar el camino para resolver el enigma, y es este el acontecimiento que le empuja a abandonar el maniqueísmo.

Así, en la filosofía platónica encuentra Agustín una primera respuesta satisfactoria: «No entendía que el mal no es sino privación del bien hasta lo que enteramente no es y que, por tanto, carece de una entidad propia». Sostiene que, si el mal fuese sustancia, entonces sería bueno, pues Dios hizo buenas todas las cosas.

La existencia de males de carácter metafísico (la propia imperfección de los seres) y natural (catástrofes naturales, enfermedad y muerte) encuentran respuesta, según el Santo, en la teoría neoplatónica de la negatividad. Pero, ¿y el mal moral, es decir, tanto el daño producido a voluntad por los seres humanos -injusticia, engaño, traición...-, como el que padecemos por nuestro propio carácter de seres inteligentes y libres — tristeza, desengaño, soledad...—?

Agustín responde con el libre, pero torcido albedrío humano. Las causas del sufrimiento moral son el mal que elegimos hacer y el recto juicio divino que nos castiga. Es el Dios retributivo del Antiguo Testamento que premia a los buenos y castiga a los malos. Define este mal como "perversidad de la voluntad» (VII, $17,22)$, un pecado que es consecuencia de la falta original de Adán que nos es imputable. La naturaleza lábil de todos nosotros nos inclina al pecado, pues nuestra voluntad ya no es completamente libre para hacer el bien, sino que se encuentra desgarrada por dos impulsos contrapuestos. Por ello, Dios nos envía el auxilio de la gracia. Para Agustín, la virtud por sí misma, sin la gracia, es vanidad. La gracia, pues, en primer lugar; la virtud, después. Se trata del misterio de la Encarnación: Dios encarnado, muerto y resucitado, comparte nuestra suerte y nos ofrece el auxilio de la gracia para vencer el pecado y la muerte que, desde Adán, nos doblegan.

El pecado original, expresión de la idea primitiva e intuitiva de que la culpa, como el honor, se extiende a través de la estirpe de una generación a otra, es la respuesta teórica a la presencia del sufrimiento y la muerte, frutos de una voluntad tortuosa y débil. Ésta es la posición de Agustín, que continúa así con la teoría de la retribución, basada, a su vez, en una concepción providencialista de Dios presente en la tradición bíblica. 
En la teoría del pecado original, está la clave de los sufrimientos: esa mancha vino a destruir la primigenia naturaleza feliz e inmortal del ser humano, afirma Agustín contra los pelagianos. Nuestro ser está viciado, nuestra libertad cuestionada o muy menguada. Dependemos de la gracia y la misericordia divinas. Ambas doctrinas, la del pecado original y la de la gracia divina, que Camus conoce a través de Agustín, aparecerán reiteradamente, desde una perspectiva crítica, en La peste y en La chute, cuyo protagonista, Clamence defiende la inocencia del nacido desde su pagano púlpito del bar México City.

El objetivo de esta teología del pecado y del Dios justiciero es salvar la bondad divina, al hacer responsable al ser humano. Por eso Blaise Pascal afirma con rotundidad: «Es necesario que nazcamos culpables, o Dios sería injusto» (Pascal, 1669, p. 237). La tesis es clara: condenamos al ser humano para salvar la inocencia divina.

\section{LA RESPUESTA DE LA TEODICEA RACIONALISTA}

Como acabamos de ver, la existencia del mal puede situar al filósofo creyente en una posición de abogado defensor de la causa de Dios. Éste es el sentido del neologismo teo-diké (teodicea), justificación de Dios con motivo del mal.

Leibniz usa por vez primera este término (Leibniz, 1710, p. I, 21). Distingue las tres clases de mal ya mencionadas y se ocupa del dolor de los inocentes, reconociendo que es causa de escándalo, pero lo justifica con estas palabras: «No sólo las aflicciones serán abundantemente compensadas, sino que incluso comportarán el incremento de nuestra felicidad; y no sólo esos males son útiles, sino que incluso son indispensables». Y es que, con su hipótesis de la armonía preestablecida en el mejor de los mundos posibles, se sitúa en un plano de generalidad tal que sus argumentos, además de indemostrables y, por lo mismo, irrefutables, son capaces de justificarlo todo: cualquier hecho, por aberrante que resulte, es admisible en un mundo cuya globalidad universal está ordenada hacia el bien supremo. Incluso en el infierno valdrían los planteamientos leibnizianos de la armonía preestablecida. Como escribió Voltaire, a los discursos del buen maestro Pangloss sólo cabe oponer la patencia de la imbecilidad, crueldad y mezquindad humanas, o bien la ciega ferocidad de los elementos naturales cuando desatan su ira. Por otra parte, los planteamientos de Leibniz, como los de otras teodiceas, se basan en un cálculo de cantidades que busca obtener el equilibrio o, mejor, la compensación del mal por la cantidad total de bienes. Pero esto parece justificar conclusiones tan crueles como que la superabundancia de la parte de la humanidad que vive bien compensaría las miserias del atribulado resto. Este planteamiento cuantitativo lleva a Leibniz a escribir, cuando se refiere al número de los salvados y los condenados, y a sus suertes respectivas, que hay «incomparablemente más bien en la gloria de todos los salvados que mal en la miseria de todos los condenados». Asimismo, a partir de este argumento, establece sutiles y alambicadas distinciones o, en el peor de los casos, plantea hipótesis extravagantes, como cuando, consciente del peso del mal en nuestro planeta (uno de los muchos mundos posibles), no tiene inconveniente en apelar a la probable existencia de seres extraterrestres felices que contrarresten en el cómputo cósmico a la legión de desgraciados terrícolas. 
La cuestión de cómo conjugar la existencia de la divinidad con la del mal afecta menos a una teología politeísta y antropomorfa como era la griega. En ella los dioses padecen envidia, se enfrentan a los mortales, son imperfectos y dependen del Destino, fuerza ciega que les supera. Diferente es el caso de los monoteísmos, que sitúan en la cúspide del cosmos a un Ser Personal, Todopoderoso y Bueno, origen y causa del universo. En este sentido se ha expresado Paul Ricoeur en Finitud y culpabilidad al sostener que el secreto de la antropología trágica es teológico: la identidad entre lo divino y lo diabólico es el nudo de esa teología y antropología que califica como trágicas. El héroe es obcecado y conducido fatalmente a su perdición por los dioses. Existe una «malevolencia» divina, fruto de la envidia o los celos. Esto es inaceptable para una razón dialéctica que deslinda con nitidez los orígenes respectivos del Bien y el Mal. Por ello, en ese contexto de amalgama entre el bien y el mal, propio de la religión griega, no tiene sentido una teodicea. Así, en Prometeo encadenado de Esquilo, el héroe se rebela contra la injusticia cometida por Zeus al dejar indefenso al ser humano. Puede hablarse así de un mal de fondo del que también son víctimas los propios dioses.

Camus rechaza la tradición teodiceica cristiana porque, además de no resolver satisfactoriamente el problema del mal, se apoya, como hemos visto, en una condena de la condición humana. Él, como otros autores ateos, protesta contra ese Dios judeocristiano que sólo se sostiene en su trono cargando en el debe del ser humano toda suerte de culpas y miserias. Estimamos inapropiado, sin embargo, considerar el ateísmo camusiano como una reacción humanista ante el Dios todopoderoso de las teologías monoteístas. Esto conduce a construir una visión negativa y simplificadora del ateísmo. Este planteamiento hace del ateísmo un pensamiento bastardo y negativo: el mal existe, luego Dios no (o, en la versión de Primo Levi: «Auschwitz existe, luego Dios no»). Llamar ateo al no creyente, abona ya esta posición por el prefijo negativo que precede al sustantivo. Pero el ateo se atiene exclusivamente a la razón —al carecer de la fe que el creyente postula como imprescindible para la creencia-, y su razón no ve argumentos convincentes para sostener la existencia de un ser que es radicalmente otro, de naturaleza diversa a toda realidad conocida. Rechaza, pues, la falacia ad ignorantiam: afirmar la existencia de algo porque nadie ha podido demostrar lo contrario. Ante esta situación, el no creyente se atiene a la existencia de la realidad fenoménica, sin aventurarse más allá. Puede incluso interpretarse la increencia como la actitud original, al no postular seres que, al menos desde el punto de vista racional, no pueden inscribirse en el discurso humano, pues su existencia es más que problemática.

Pero volvamos a Camus. Él protesta contra la posición cristiana en torno al pecado original y la necesidad de la gracia divina, que acabamos de exponer, desde su planteamiento humanista: la autonomía moral del ser humano y su inocencia originaria deben quedar en pie.

La doctrina del pecado original condena al ser humano, y, al mismo tiempo, mancilla su naturaleza al hacerla proclive al mal desde su nacimiento. El sufrimiento no es, en este contexto, más que el merecido castigo por una falta que sólo la gracia puede reparar. El ser humano es, así, un ser débil y esclavo de su propia condición. Este aspecto es, en opinión de Camus, el más oscuro del cristianismo y las filosofías racionalistas. Para él, constituyen la justificación teórica de una injusticia (Camus, 1964, p. 112). Cuando le acusen de pesimismo, responderá afirmando que es el 
cristianismo quien proclama la miseria de las criaturas o quien ha sostenido la condenación de los niños no bautizados. La imagen de un Dios terrible y todopoderoso tiene expresiones tan crueles como la muerte de los primogénitos en Egipto, ordenada por Dios como castigo (Éxodo: 12, 29); o los textos bíblicos en que la peste aparece como azote de Yahvé a sus enemigos (Éxodo: 9, 15; Levítico: 26, 25; Deuteronomio: 28, 21; Jeremías: 14, 12; 21, 7 y 9; 24, 10; Ezequiel: 5, 12; 7 , 15.). Camus recoge estos textos con exhaustividad en sus Carnets (Camus, 1964, p. 66), y establece una dicotomía entre el reino de la gracia divina y el de la justicia humana (Camus, 1951, pp. 510-11), una justicia que ha de ser conquistada desde la rebeldía (p. 629).

Para él, gracia y rebeldía son nociones anejas a mundos diferentes: el cristiano y el griego, respectivamente. Así lo afirma en «Remarque sur la révolte» (Camus, 1945, pp. 1682-1697), artículo aparecido cuando aún no se han publicado las principales obras de la rebeldía, pero que contiene ya germinalmente las ideas fundamentales que vertebrarán el ensayo L'homme révolté. No hay para el espíritu humano más que dos universos posibles: el de lo sagrado — que es el de la gracia-, y el de la rebeldía — que es el de la justicia- (p. 1688). En el ámbito de lo sagrado no cabe sino una rebeldía desvirtuada - que denomina «rebeldía metafísica»-porque, en su opinión, el auténtico rebelde se sitúa fuera del contexto religioso. En éste, las respuestas están dadas todas ellas de una vez y, por esta razón, afirma Camus, la filosofía se diluye en la religión y acaba siendo reemplazada por el mito.

\section{El tiempo y el SILENCIO}

La condición humana es frágil y está herida por la finitud, pues somos palabra en el tiempo. El tiempo y el silencio son los dos mejores contraargumentos ante la acusación o condena genérica de la naturaleza humana. Para Camus no cabe hablar ni de culpa absoluta (contra las filosofías racionalistas, en especial el idealismo hegeliano y sus adláteres), ni tampoco de culpa universal (contra el cristianismo). Tan solo de responsabilidad relativa y restringida, claro está, al mal moral y, sólo excepcionalmente, al mal físico o natural.

La vida es un tesoro que se escurre entre las manos, un breve paréntesis entre dos inconmensurables vacíos existenciales. El tiempo no es más que un artificio creado para medir la distancia que nos separa de la muerte. La vieja inscripción en la esfera del reloj del campanario de Lourmarin que Camus podía contemplar desde su casa, nos lo sigue recordando hoy: «Horae, dum saltant, nostras vorant» («Las horas, mientras saltan, nos devoran»). Además de la finitud del tiempo, la «maldición del tiempo» (o el «eterno presente») son dos constantes de la obra camusiana.

Y el silencio, el de la incomunicación entre los solitarios que todos somos a la postre, el de no poder expresar lo que se desea o se siente, el de no haber hallado la palabra necesaria en el momento preciso, el silencio de la incomprensión, el de la falta de palabras o el del exceso de las mismas en nuestra sociedad de la hipercomunicación en superficie. También el silencio impuesto a las víctimas cuando el ruido del poder acalla la voz de la legión de los vencidos. Y, como colofón, 
el silencio definitivo de la muerte, el olvido y la nada. «Ese silencio que se cierne sobre los lechos donde mueren los hombres», en palabras del doctor Rieux; la última de las imposiciones del tirano en L'état de siège.

La finitud del ser y del verbo. Ambas tan próximas y familiares para Camus cuya vida, que pendía amenazada por una incurable y temprana enfermedad, comenzó junto a una madre impedida, silenciosa.

Por eso, a la teodicea, Camus opone su antropodicea: ahora el reo juzgado y exonerado ante los cargos del mal no es Dios, sino el propio ser humano. En L'homme révolté se define la teodicea como una expresión entre otras de la rebelión metafísica que Camus rechaza, y cuyo rasgo principal es una insatisfacción profunda con la existencia humana. Esta rebeldía espuria se aparta del carácter humanista y generoso del movimiento original de la rebeldía contra la injusticia que, según Camus, compartimos todos los humanos. Hay un rebelde metafísico ateo y otro religioso, pero ambos sienten el mismo rechazo por el universo. Para mostrarlo, recoge unas palabras de Sade que para él es el primer rebelde metafísico ateo de la historia (excepción hecha de Epicuro): «Aborrezco la naturaleza... Quisiera trastornar sus planes, resistir su marcha, detener la rueda de los astros, revolver los globos que flotan en el espacio, destruir lo que la sirve, proteger lo que la perjudica; en una palabra, insultarla en sus obras, y no puedo conseguirlo» (Citado en Camus, 1951, p. 455). Tal insatisfacción lleva a buscar responsables del mal y, descartada la responsabilidad humana, al menos en lo tocante a algún tipo de mal (metafísico y físico), el dedo acusador se dirige a Dios. El ateo lo niega — según la fórmula de Stendhal: «La única excusa de Dios es que no existe»-, el creyente, lo justifica; pero, para Camus, ambos están situados en un mismo contexto de resentimiento y rechazo de un mundo que no les satisface.

El amor, el amor fati, redime de esa insatisfacción existencial y metafísica (Camus, 1951, p. 708), nos reconcilia con la existencia y hace inútil la teodicea. Por eso Nietzsche, según Camus, renunció a toda forma de rebeldía metafísica contra el mundo y recurrió a Heráclito (p. 482 y sigs.), para, equiparando libertad con heroísmo, definir aquélla como la adhesión apasionada al propio sino en todas sus dimensiones, propugnando una aceptación del destino en su totalidad. En esto consiste el amor fati. El mundo es imperfecto, y el mal, contra Agustín, no posee un carácter más privativo que el bien. No cabe hablar, tampoco, de otros mundos posibles donde el mal no exista, contra Leibniz. Ni el mal ni el bien exigen justificación: «Negamos a Dios, negamos la responsabilidad de Dios; sólo así liberamos al mundo», es la consigna de Nietzsche; la de Camus, "no se puede juzgar al mundo» (p. 475).

Camus hace responsable al cristianismo de la rebeldía metafísica, estableciendo una estrecha dependencia entre el Dios personal cristiano y la actitud moderna de negación radical frente a una realidad insatisfactoria: un ser más allá de todo límite tiene como corolario inevitable una rebelión humana de exigencias desmesuradas, nos viene a decir (pp. 438-439). Por ello el héroe trágico encarnado en Prometeo es tan dispar al rebelde metafísico contemporáneo: aquél está contenido en su acción por la mesura; se rebela contra Zeus y contra su juicio a la hora de conceder dones al ser humano, pero no lo hace contra el mundo en general: «Es que la rebeldía metafísica supone una visión simplificada de la creación que los griegos no podían tener. Para ellos no estaban los dioses de un lado, y los hombres, de otro, sino 
grados que conducían de los últimos a los primeros. La idea de la inocencia opuesta a la culpabilidad, la visión de una historia toda ella resumida en la lucha del bien y del mal les era ajena» (pp. 439-440).

Contra lo que opina Michel Onfray en su biografía que destaca la raíz libertaria del pensamiento camusiano (Onfray 2012), Camus no niega el concepto de falta o pecado en la tradición griega. La culpabilidad no es un invento cristiano, pero la condena sin paliativos sí es característica del monoteísmo.

En el judeocristianismo aparece la noción del dios personal, creador y responsable de todas las cosas: esto explica, según Camus, el surgimiento de la protesta radical expresada en la rebeldía desmesurada, la rebeldía metafísica: «La historia de la rebeldía es inseparable de la del cristianismo en el mundo occidental» (Camus, 1951, p. 440). Por el contrario, la rebeldía humanista contra la injusticia, incompatible con el concepto cristiano de la gracia, se desarrolla en el contexto de la cultura griega, siendo Prometeo el primer modelo de la protesta filantrópica que halla Camus. La rebeldía metafísica, como también las revoluciones históricas iniciadas en el XVIII, son meras desvirtuaciones de esa primera y original rebeldía que Camus quiere rescatar con su "pensamiento solar o de mediodía», que, para él, encarnan los países del sur, y que, desde su ateísmo humanista, pretende erigir frente a la injusticia y el nihilismo contemporáneo.

\section{LA REBELDÍA HUMANISTA Y LA EDUCACIÓN SOCRÁTICA}

Cuando las protestas de los indignados contra las desigualdades y las democracias cautivas de los intereses del gran capital han recorrido multitud de países, cobran nuevo vigor las palabras de Camus para quien el espectáculo de la rebeldía y la fraternidad humanas ante la injusticia es el más bello que pueda contemplarse. Pero ¿quién es este rebelde camusiano a quien nuestro autor consagró un ensayo que vino a costarle la ruptura con la izquierda oficial, el Existencialismo y el Surrealismo?

El propio Camus supone también un modelo de rebeldía para nuestros días al enrolarse en las filas de indignados que no hallan reposo ni en Dios, ni en la Historia, ni tampoco en la Realpolitik. Nos ofrece un pensamiento mundano, práctico y comprometido, un arte de vida para tiempos de catástrofe, lejos de los derroteros habituales de la filosofía más academicista.

La primera consecuencia del mal es el absurdo, el derrumbe de los referentes de sentido habituales. Pero cabe una construcción de sentido relativo a través de la rebeldía humanista, generadora de valores morales. «Me rebelo, luego somos» es, en Camus, la expresión de la protesta de quien padece opresión e injusticia. Del absurdo a la rebeldía, del yo al nosotros es el camino del rebelde camusiano. La rebeldía es una dimensión esencial en nuestra existencia: es una categoría de la vida humana (junto al absurdo y el amor), que nace de la intuitiva percepción de nuestra dignidad compartida.

Camus defiende la existencia de principios morales inviolables, tanto para la acción individual, como para la gestión política. Impone, así, exigencias a la praxis transformadora. "Tantas exigencias que, a la postre, se trata de una rebeldía 
inviable», le reprochará Sartre, su gran oponente. Y contra La Peste escribirá Les mains sales, que aparece publicada un año después, en 1948. Pero las revoluciones históricas nos han mostrado el peor rostro del nihilismo cuando no han estado sujetas a límites morales claros. Y Camus quiere poner cota a un peligroso relativismo moral al que nos abocan otras filosofías del absurdo como la de Sartre. Tal relativismo puede ser tan destructivo como, en el idealismo alemán y sus herederos, lo es la deificación de los valores de la eficacia y del devenir histórico. El papel de la educación formal es aquí incuestionable, en orden a la transmisión de valores humanistas, centrados en la inviolable dignidad de cada persona.

Camus concede una crucial importancia a la educación formal y no formal en su obra, y reconoce la capacidad emancipadora e igualitaria de la escuela ${ }^{4}$. Como es conocido, él deseaba opositar a una plaza de profesor de filosofía en un centro de enseñanzas medias, pero su tuberculosis le impidió presentarse a las pruebas. En su obra, se siente profundamente deudor de sus primeros educadores, tanto de la escuela como del liceo. Y, respecto a los lugares de aprendizaje no formal, reconoce los valores que aprendió como portero de un equipo de fútbol y como miembro de compañías teatrales: la amistad o el compañerismo, la generosidad en el triunfo y en la derrota, o el poder de la colaboración en proyectos comunes.

Durante mi estancia en el archivo Albert Camus en Aix-en-Provence (Francia) ${ }^{5}$, pude consultar «La réforme de l'enseignement?», un texto inédito manuscrito al dictado por Francine Camus con correcciones, también manuscritas, del propio Albert. Aquí plantea su concepción de una enseñanza humanista y liberadora. Tras comenzar lamentando la parálisis del sistema educativo francés, sostiene que no se educa para una sociedad insatisfactoria desde el punto de vista de la felicidad y la justicia, sino en pro de un mejor modelo de convivencia. «Si pensamos que la fatalidad histórica existe, que es el producto de una dialéctica soberana; si admitimos con Hegel y toda la filosofía moderna que el hombre es hecho para la historia y no la historia para él, entonces debemos ajustarnos a los acontecimientos, hacernos los más fuertes en el mundo de la fuerza y enseñar, en una palabra, la voluntad de poder». Camus habla, sin duda, del modelo competitivo de enseñanza, frente al cual propone un modelo colaborativo, integrador y dialogante — socrático lo denomina él—; pues «lo más opuesto a la voluntad de poder es el diálogo (...) Enseñar el diálogo es enseñar la modestia, la existencia de los seres humanos y el ejercicio de la comprehensión. Es oponerse a enseñar la muerte, es decir, la filosofía de la historia. Es dar una oportunidad a la vida». Y añade: «La enseñanza superior será socrática o no será». El modelo dialógico o socrático conjuga dos poderosos métodos de aprendizaje: el diálogo y la mayéutica. Ambos instrumentos harían del socratismo la primera versión histórica de las pedagogías constructivistas en las que el docente acompaña al discente en el proceso generativo del conocimiento.

4 Cfr. «L'enseignement (Misère de la Kabylie)», artículo aparecido el 11 de junio de 1939. Actuelles III, Chroniques Algériennes, Oeuvres, II, 919-923.

5 Agradezco a la dirección del Centre de Documentation Albert Camus-Cité du Livre, en Aixen-Provence, las facilidades ofrecidas para la consulta del valioso fondo que alberga. Algunos de esos documentos fueron ya mencionados en la conferencia que, bajo el título "Albert Camus: el tiempo y el silencio», pronuncié en la Universidad Autónoma del Estado de México, en Toluca, en el Congreso Internacional «Albert Camus en el centenario de su nacimiento», celebrado entre los días 4 y 7 de noviembre de 2013. 
En el modelo competitivo, nos dice Camus, solo se persigue una formación profesional y técnica. Pero, «si tomamos partido por la rebeldía humanista (...), debemos enseñar a nuestros niños, no a ser los más fuertes sino a ser los más veraces». En este caso, habremos de formarlos en la reflexión crítica y el diálogo. La filosofía de la historia emanada del idealismo alemán supone «una mutilación del ser humano», así como un "ejercicio de silencio o de monólogo colectivo (...) Enseñar el diálogo implica enseñar que no se puede tener razón ni ser libre contra nuestros semejantes; es enseñar la modestia, la existencia de los otros y el ejercicio de la compasión».

Ideas similares hallamos en su discurso del 19 de julio de 1951 en un acto organizado por la Casa de Cataluña en los locales parisinos de la Liga Francesa de la Enseñanza, al que asiste Octavio Paz, amigo de Camus. También en su intervención del 22 de febrero de 1952 en la Sala Wagram (Camus, 1953, p. 781), "L'Espagne et la culture», donde se refiere al carácter liberador de la educación. Y en octubre de 1959, al hacerse eco de las palabras del pedagogo español Ferrer i Guàrdia: «Todo el mal que existe en el mundo procede de la ignorancia» (palabras casi idénticas escribe el cronista de La Peste, el doctor Rieux).

La educación constituye un poder transformador profundo y duradero. Es la mayor fuerza revolucionaria que existe, pero no cualquier tipo de educación. A veces, las instituciones educativas se convierten en reductos del poder donde se adoctrina para el sistema vigente sin cuestionar en ningún momento sus propios fundamentos. Camus fue siempre consciente de la importancia de sus educadores. Louis Germain, su maestro de escuela, o Jean Grenier, su profesor de filosofía en el instituto, con quien mantuvo una fructífera relación intelectual durante toda su vida. A él dedica dos de sus más importantes obras: L'envers et l'endroit y L'Homme révolté.

Una educación universal, pública, laica —es decir, no segregadora- y gratuita es un instrumento esencial de la rebeldía humanista camusiana. De esto creo que se ha hablado poco. El propio Camus es un magnífico ejemplo de cómo un sistema educativo público e integrador, no excluyente, verifica una labor compensatoria de las desigualdades iniciales. Él pertenecía a una familia pobre. Huérfano de padre, su madre mantenía a sus dos hijos con los exiguos ingresos que obtenía limpiando casas. Su destino parecía estar escrito: seguir los pasos de Lucien, su hermano mayor, abandonar la escuela una vez concluida la enseñanza elemental, única gratuita por entonces. Pero su maestro Germain vio algo especial en el niño que se emocionaba con la lectura de Croix de bois, de Roland Dorgelès. Se empeña en convencer a la familia de que Albert se presente a las pruebas para conseguir una beca estatal que le permita seguir estudios de bachillerato sin grandes sacrificios. La abuela materna — nacida en Sant Lluís, Menorca-, que ha acogido a la viuda y sus hijos tras el fallecimiento del marido, se niega rotundamente: el niño debe trabajar para aportar al sustento familiar. Pero la madre, analfabeta y prácticamente sorda, sale de su mutismo habitual para acceder a la petición del maestro: «Albert hará el bachillerato». Camus no olvida nunca este valeroso gesto del profesor que le arrancó del destino de los desheredados y le permitió acceder a una formación académica. Su discurso de aceptación del Nobel de 1957 lo dedica a Louis Germain quien, como todo buen maestro, fue capaz de obrar maravillas en la mente inquieta y curiosa de aquel niño. 
Los valores de la rebeldía humanista camusiana han de hallarse en el corazón mismo de la experiencia rebelde (Camus, 1952). La solidaridad entre personas libres y dignas (no la eficacia ni el poder) es la fuente de esta moral rebelde limitada por «la medida de las cosas y del ser humano». Es lo que él denomina la pensée de midi, inspirado en la mesura (Camus, 1951, p. 702) que Heráclito simbolizó con la diosa Némesis y que, según Camus, exige:

- En primer lugar, el reconocimiento del otro como diferente de mí, pero igual a mí en dignidad. Con el consiguiente rechazo de cualquier acción individual o colectiva que ponga en jaque esa dignidad inviolable y compartida, como es el caso de la pena de muerte y el asesinato en general.

- La generosidad y la solidaridad fraternas como remedios al nihilismo contemporáneo.

- Defensa del diálogo entre iguales como vía de solución de conflictos frente a la imposición dogmática de ideas.

- Reivindicación del valor clásico del honor, entendido como fidelidad a la promesa y como integridad moral. A ello se refiere, por ejemplo, en «L'Espagne et le donquichottisme», conferencia pronunciada en La Sorbona el 23 de octubre de 1955 en un homenaje a Cervantes organizado por la revista libertaria de la CNT española Solidaridad Obrera (Solidaridad Obrera, 1955, p. 1); así como en «Fidélité à l'Espagne», prefacio al número especial de la revista Témoins en apoyo a la República española en el exilio (Témoins, 1956, pp. 4-5).

- La justicia y el derecho como tareas inacabables e irrenunciables; y el apoyo a las instituciones democráticas que los administran, fundadas en la soberanía popular.

- Defensa de la libertad. Justicia y libertad han de conjugarse dialécticamente, de manera que cada una de ellas halle su medida en el límite de la otra.

- El rechazo de la violencia como instrumento para alcanzar los fines propuestos (incluida la razón de Estado). La violencia ha de permanecer siempre como el último recurso al que se acude cuando las vías del diálogo están agotadas o resultan intransitables, y ha de ejercerse en todo caso en favor de las instituciones democráticas (Camus, 1951), nunca en nombre de ideales o doctrinas.

- Al elegir los medios para alcanzar el fin propuesto, la eficacia no será el valor primordial a considerar, sino el respeto a la dignidad humana, junto con la aspiración a las mayores cotas posibles de libertad.

- Y la negación de una justicia mitificada, sea ésta trascendente (divina) o inmanente y aplazada sine die en forma de utopía histórica. Se trata, más bien, de la urgencia de la justicia y la reparación de las víctimas aquí y ahora.

Esta actitud exigente de fidelidad a principios éticos implica el riesgo de la ineficacia a corto plazo, pero elegir la vía opuesta es, lo sabemos tras siglos de revoluciones, adentrarse por la senda del terror y la injusticia (Camus, 1951, p. 697).

La moral camusiana se edifica de este modo sobre el categórico carácter inviolable de la vida de cada ser humano, el único fin en sí mismo no supeditable a ningún otro valor o principio. La dignidad es para todos, o no es para nadie. La libertad, también. Por eso, no habrá auténtica democracia en ningún país del mundo mientras quede un solo pueblo sometido a la tiranía del totalitarismo, sea este político, económico o religioso. 


\section{CONCLUSIÓN}

Para Camus, sus años de lucha en la Resistencia llenos de sufrimiento, pero también de esperanza, se vieron recompensados por la liberación del yugo nazi. Sin embargo, pocos años después, esa esperanza se vio defraudada. En la Rusia soviética, el comunismo de Stalin ofrecía su peor rostro en el Gulag, poniendo de manifiesto el precio que se paga por una escatología histórica mitificada o historiodicea. Al mismo tiempo, sus tres patrias ofrecían un rostro desolado diez años después del fin de la Guerra: en Francia, el París de la intelectualidad de Saint-Germain-des-Près, habitado por los «nihilistas de salón» encabezados por Sartre; Argelia se desgarraba en una guerra civil; y España yacía sometida al yugo de la dictadura franquista que, para más oprobio, recibía los parabienes de las democracias occidentales (las «democracias del dinero» las llama Camus), mientras muchos de sus mejores hijos padecían el exilio, la cárcel o el paredón de fusilamiento. Reaparecía la tragedia, lo relativo y frágil de cualquier avance humano, la confrontación perpetua entre lo necesario y lo posible. En efecto, el bacilo de la peste no puede ser erradicado. ¿De qué había servido el sacrificio de millones de víctimas? En 1955, en el prefacio que escribe para la obra de Konrad F. Bieber (1954, p. 10), Camus se lamenta de la frágil memoria humana: "Estas luchas habrían debido comportar una enseñanza perdurable. Creo que hoy no queda nada de eso (...) Esta experiencia de un gran deseo de paz traicionado, y contrapuesto a una guerra insoportable, no ha servido de casi nada a la mayor parte de los que la han vivido (...) No ha servido de nada a muchos intelectuales de la Resistencia que se encaminan hoy por el rodeo de los mismos sofismas, hacia una nueva colaboración (con el comunismo estalinista)».

La democracia y la justicia constituyen una promesa, un proyecto siempre inacabado. Y Camus, consciente de nuestra condición trágica, y a pesar de los desengaños, creyó en los que, como el doctor Rieux, siguen dispuestos a combatir el bacilo de la peste en nombre de su valeroso humanismo. Como Rieux, su álter ego, era, tal vez, «un hombre cansado del mundo en que vivía, pero inclinado hacia sus semejantes y decidido a no claudicar ante la injusticia y las concesiones».

Por eso continuó con su batalla intelectual por un mundo mejor hasta el final de sus días al lado de los anarquistas españoles, de las víctimas civiles de la guerra argelina o de los primeros objetores de conciencia. Y, como el maestro Paulo Freire, lo hizo con amor y con rabia: la rabia del rebelde que no tolera la injusticia, y el amor a la vida y a la condición humana.

\section{BiBLIOGRAFÍA}

\section{Obras de Albert Camus citadas:}

Los números I y II en las citas de Camus, corresponden a la edición de sus obras completas en la editorial Gallimard. Así, Euvres I. Théâtre, récits, nouvelles, 1962. París : Gallimard (Bibliothèque de la Pléiade) ; y Euvres II. Essais, 1965. París : Gallimard (Bibliothèque de la Pléiade).

- 1936, Métaphysique chrétienne et Néoplatonisme, en Euvres II.

- 1937, L'envers et l'endroit, en Euvres II. 
- 1939, Noces, en Euvres II.

- 1942, L'Étranger, en Euvres I.

- 1942, Le Mythe de Sisyphe, en Euvres II.

- 1944, Le malentendu, en CEuvres I.

- 1945, Remarque sur la révolte, en Euvres II.

- 1947, La peste, en Euvres I.

- 1948, L'état de siège, en Euvres I.

- 1951, L'homme révolté, en Euvres II.

- 1952, Révolte et romantisme, en Euvres II.

- 1953, Actuelles II. Chroniques 1948-1953, en Euvres II.

- 1956, La chute. Paris : NRF.

- 1957, Réflexions sur la guillotine, en Euvres II.

- 1957, Les muets, en L'Exil et le royaume, en Euvres I.

- 1964, Carnets II 1942-1951. Paris : Gallimard.

\section{Otras obras citadas :}

Bieber, K. F. y Camus, A. (préface) (1954), L’Allemagne vue par les écrivains de la Resistance Française. Genève: Librairie Droz.

Jonas, H. (1972), El principio vida. Hacia una biología filosófica, 2000. Traducción de José C. Mardomingo Sierra. Madrid: Trotta.

Leibniz, G. W. (1710), Teodicea o Tratado sobre la libertad del hombre y el origen del mal, 1928. Traducción de E. Ovejero y Maury. Madrid: Aguilar.

Marin, L. (2013), Albert Camus. Écrits libertaires 1948-1960. Montpellier: Indigène Éditions.

Onfray, M. (2012), L'ordre libertaire. La vie philosophique d'Albert Camus. Paris: Éditions J'ai Lu.

Pascal, B. (1669), Pensamientos, 1981. Traducción de Carlos R. De Dampierre. Madrid: Alfaguara.

Ricoeur, P. (1960), Finitud y culpabilidad, 1969. Traducción de Cecilio Sánchez Gil. Madrid: Taurus. Solidaridad Obrera (Revista), n. ${ }^{\circ}$ 554, 1955.

- (1956). Témoins (Revista), n. ${ }^{\circ} 12-13$.

San Agustín (397-398), Confesiones, 1964. Traducción de Valentín M. Sánchez Ruiz. Madrid : Apostolado de la Prensa, S.A.

Voltaire (1764), Diccionario Filosófico, 1995. Traducción de Ana Martínez Rincón. Madrid: Temas de Hoy.

Universidad de Almería

Ángel Ramírez Medina

Grupo de Investigación Lenguaje y Pensamiento:

relaciones de significación en el léxico y en obras literarias

angelr.medina@hotmail.com

[Artículo aprobado para publicación en enero de 2018] 